\title{
Identification of research trends concerning application of stent implantation in the treatment of pancreatic diseases by quantitative and biclustering analysis: a bibliometric analysis
}

\author{
Xuan Zhu ${ }^{1,2}$, Xing Niu ${ }^{3}$, Tao Li ${ }^{4}$, Chang Liu ${ }^{5}$, Lijie Chen ${ }^{6}$, Guang Tan ${ }^{\text {Corresp. } 7}$ \\ 1 \\ ${ }^{1}$ Department of Pancreatic and Biliary Surgery, First Affiliated Hospital of China Medical University, Shenyang, Liaoning, China \\ Department of General Surgery, Anshan Hospital, First Affiliated Hospital of China Medical University, Anshan, Liaoning, China \\ 3 Department of Second Clinical College, Shengjing Hospital affiliated to China Medical University, Shenyang, Liaoning, China \\ 4 Department of General Surgery, Fushun Mining Bureau General Hospital, Fushun, Liaoning, China \\ 5 Department of General Surgery, First Affiliated Hospital of China Medical University, Shenyang, Liaoning, China \\ 6 Department of Third Clinical College, China Medical University, Shenyang, Liaoning, China \\ 7 Department of Hepatobiliary Surgery, First Affiliated Hospital of Dalian Medical University, Dalian, Liaoning, China \\ Corresponding Author: Guang Tan \\ Email address: guangtan@dmu.edu.cn
}

Objectives: In recent years, with the development of biological materials, the types and clinical applications of stents have been increasing in pancreatic diseases. However, relevant problems are also constantly emerging. Our purpose was to summarize current hotspots and explore potential topics in the fields of the application of stent implantation in the treatment of pancreatic diseases for future scientific research.

Methods: Publications on the application of stents in pancreatic diseases were retrieved from PubMed without language limits. High-frequency Medical Subject Headings (MeSH) terms were identified through Bibliographic Item Co-Occurrence Matrix Builder (BICOMB). Biclustering analysis results were visualized utilizing the gCLUTO software. Finally, we plotted a strategic diagram.

Results: 4087 relevant publications were obtained from PubMed until May $15^{\text {th }}, 2018.83$ high-frequency $\mathrm{MeSH}$ terms were identified. Biclustering analysis revealed that these high-frequency MeSH terms were classified into 8 clusters. After calculating the density and concentricity of each cluster, strategy diagram was presented. The cluster 5 "complications such as pancreatitis associated with stent implantation" was located at the fourth quadrant with high centricity and low density.

Conclusions: In our study, we found 8 topics concerning the application of stent implantation in the treatment of pancreatic diseases. How to reduce the incidence of postoperative complications and improve the prognosis of patients with pancreatic diseases by stent implantation could become potential hotspots in the future research. 
1 Identification of research trends concerning application of stent implantation

\section{in the treatment of pancreatic diseases by quantitative and biclustering}

\author{
analysis: a bibliometric analysis
}

\section{Running title: Stent implantation in pancreatic diseases}

Xuan Zhu, Xing Niu, Tao Li, Chang Liu, Lijie Chen, Guang Tan*

Xuan Zhu, Department of Pancreatic and Biliary Surgery, First Affiliated Hospital of China Medical University, \& Department of General Surgery, Anshan Hospital, First Affiliated Hospital of China Medical University, No.155 Nanjing North Street, Heping District, Shenyang 110001, Liaoning Province, China. 2382942812@qq.com

Xing Niu, Department of Second Clinical College, Shengjing Hospital affiliated to China Medical University, NO.36 Sanhao Street, Heping District, Shenyang 110004, Liaoning Province, China.605398920@qq.com

Tao Li, Department of General Surgery, Fushun Mining Bureau General Hospital, No.24 Central Street, Xinfu District, Fushun 113008, Liaoning Province, China.1309359604@qq.com Chang Liu, Department of General Surgery, First Affiliated Hospital of China Medical University, No.155 Nanjing North Street, Heping District, Shenyang 110001, Liaoning Province, China.466040666@qq.com

Lijie Chen, Department of Third Clinical College, China Medical University, NO.77 Puhe Road, Shenyang North New Area, Shenyang 110122, Liaoning Province, China. 2084534914@qq.com

Supportive foundations: Not applicable.

Author contributions: Tan G conceived and designed the study. Zhu X, Niu X conducted most of the experiments and data analysis, and wrote the manuscript. Li T, Liu C and Chen LJ participated in collecting data and helped to draft the manuscript. All authors reviewed and approved the manuscript.

Conflict-of-interest statement: The authors declare no conflicts of interest.

Correspondence to: Guang Tan, Professor, Department of Hepatobiliary Surgery, First Affiliated Hospital of Dalian Medical University, No.222 Zhongshan Road, Dalian 116027, Liaoning Province, China. guangtan@dmu.edu.cn 
37

\section{Abstract:}

Objectives: In recent years, with the development of biological materials, the types and clinical applications of stents have been increasing in pancreatic diseases. However, relevant problems are also constantly emerging. Our purpose was to summarize current hotspots and explore potential topics in the fields of the application of stent implantation in the treatment of pancreatic diseases for future scientific research.

Methods: Publications on the application of stents in pancreatic diseases were retrieved from PubMed without language limits. High-frequency Medical Subject Headings (MeSH) terms were identified through Bibliographic Item Co-Occurrence Matrix Builder (BICOMB). Biclustering analysis results were visualized utilizing the gCLUTO software. Finally, we plotted a strategic diagram.

Results: 4087 relevant publications were obtained from PubMed until May $15^{\text {th }}, 2018.83$ highfrequency MeSH terms were identified. Biclustering analysis revealed that these high-frequency MeSH terms were classified into 8 clusters. After calculating the density and concentricity of each cluster, strategy diagram was presented. The cluster 5 "complications such as pancreatitis associated with stent implantation" was located at the fourth quadrant with high centricity and low density.

Conclusions: In our study, we found 8 topics concerning the application of stent implantation in the treatment of pancreatic diseases. How to reduce the incidence of postoperative complications and improve the prognosis of patients with pancreatic diseases by stent implantation could become potential hotspots in the future research.

Key words: Hotspots; Stents; Pancreatic diseases; Bibliometrics; MeSH terms

\section{Introduction:}

In recent years, stents play an increasingly essential part in pancreatic diseases such as plastic stents, self-expanding metal stents, biodegradable stents, radioactive particle stents and so on. As an example, the covered metal stents reduce the incidence of complications of biliary obstruction caused by pancreatic cancer. It has been reported that percutaneous insertion of short metal stents supplies for a secure treatment, which is beneficial for patients in resectable pancreatic head cancer with jaundice [1]. With in-depth research, an irradiation pancreatic stent may provide longer patency and better patient survival [2]. And endoscopic application significantly improves the therapeutic effect of pancreatic stent [3]. Pancreatic cancer is a common digestive system cancer with high mortality. And the 5 -year survival rate has increased from $3 \%$ to $8 \%$ over the past decade years [4-5]. So far, surgical resection is the only possible treatment option. However, postoperative complications worsen the patient's prognosis and have been one of the leading causes of death after surgery. Multiple plastic stents or covered selfexpandable metallic stent could relief bile duct stricture caused by chronic pancreatitis [6].

There have been few studies on the application of stents in pancreatic diseases by use of bibliometrics. Bibliometric method, as a quantitative analysis method, is used to determine the evolution of science exploration over the past decade years [7-8]. Co-word analysis is an 
important scientometric method for identifying research hotspots in a certain field. Co-word analysis was proposed by French bibliographers in the 1970s. Its principle is mainly to count the frequency of simultaneous occurrence of words in the literature. The clustering analysis, association analysis, multi-dimensional scale analysis and other methods are utilized to analyze the relationship between words [9]. Therefore, co-word analysis can be used to outline the current state of literature research in a field and to predict the future trends [10]. Co-word analysis method reveals the intricate relationships between many objects in an intuitive way such as numerical values and graphics. Therefore, it can avoid the subjective problems brought by the previous reviews which were summarized by authors. Cluster analysis can be used to obtain semantic relationships for research topics [12]. In our study, we made double-clustering analysis, which can cluster the rows and columns of a matrix simultaneously [13]. Therefore, it can easily cluster global information and analyze high-dimensional data. The strategic diagram is used to describe the internal contact situation and the interaction between the fields in a research field based on the co-word matrix and clustering analysis, and further analyze the development of research hotspots in a certain subject. The strategic diagram displays the positional relationship of the clusters in the plane coordinates in a visual form. The quadrant structure and changes of the research subject are described according to the position and variation of the quadrant of the cluster.

Hence, we constructed a bibliometric analysis by co-word analysis and visualization concerning the application of stents in pancreatic diseases. And strategic diagram was established to explore the development status.

\section{Materials and methods:}

\section{Data obtaining}

All publications came from PubMed without the restrictions of languages. The PubMed database has been used to retrieve data in some of the biomedical research [14, 15]. PubMed is chosen not only because of the authority and breadth of the literature, but also the normative nature of the Medical Subject Headings (MeSH) keywords, more importantly. MeSH has been applied to index and catalog articles in PubMed. In our study, we collected literature on the application of stents in pancreatic diseases on May $15^{\text {th }}, 2018$, in order to ensure more current research results. Our research strategy was as follows: ("stents"[MeSH Terms] OR "stents"[All Fields] OR "stent"[All Fields]) AND (("pancreas"[MeSH Terms] OR "pancreas"[All Fields] OR "pancreatic"[All Fields]) OR ("pancreatitis"[MeSH Terms] OR "pancreatitis"[All Fields])) and "2018/05/15" [PDAT]. Publication trends were retrieved from GoPubMed (http://www.gopubmed.org) [16].

\section{Literature screening criteria}

If a paper concerning application of stents in pancreatic diseases was an original article, we would accept the literature. Meanwhile, media coverage and science briefings were excluded. Furthermore, two researchers separately examined the papers by title, abstract and full text. One researcher excluded 20 articles, and the other researcher excluded 19 articles. And the agreement was $95 \%$, which suggested a strong correlation [17]. Finally, title, author, institution, country, 
116

117

118

119

120

121

122

123

124

125

126

127

128

129

130

131

132

133

134

135

136

137

138

139

140

141

142

143

144

145

146

147

148

149

150

151

152

153

154

155

publication year and MeSH terms of available articles were saved into a new file in XML.

\section{Data extraction and analysis}

XML file was imported into BICOMB for data extraction [18-20]. And authors, journals and the frequency ranking of MeSH terms were determined [21, 22]. According to $\mathrm{H}$ index, the terms were first sorted in descending order of terms. Then the high-frequency major MeSH terms were identified if a term with frequency greater than or equal to its sequence number (h) from the list of high frequency terms, and $\mathrm{h}$ was the threshold for intercepting high frequency terms. Then the relationships between the high-frequency major MeSH terms and the source literature were determined utilizing biclustering analysis. And a binary matrix was produced using the source literature set generated by BICOMB and the high-frequency MeSH terms as columns and rows.

\section{Cluster analysis}

Then, double clusters and visual analysis were performed by "gCLUTO" version 1.0 software. "gCLUTO" is a graphical cluster toolkit and graphical front-end of the "CLUTO" data clustering library [23, 24]. The clustering analysis was employed to assess the high-frequency MeSH terms. The clustering method was used to repeat the bisection, cosine as the similarity function, and I2 as the clustering criterion function. By use of different numbers of clusters, 2 clusters were performed to differentiate the first-rank number of clusters. And the visualizations of high frequency and high-frequency bifocal results with $\mathrm{MeSH}$ article were constructed by use of Alpine and Matrix. By means of the semantic corrections between the MeSH terms and the content of typical articles in every group, the relevant topics on the application of stents in pancreatic diseases were obtained. And we made a visualized matrix biclustering of highfrequent major MeSH terms and PubMed Unique Identifiers (PMIDs) of articles on the application of stents in pancreatic diseases.

\section{Strategic diagram analysis}

A two-dimensional table is depicted by plotting themes based on centricity and density. The X-axis stands for centrality, namely the closeness between keywords within this category and those within other categories. It indicates the degree of interaction between a subject area and other subject areas. The Y-axis represents density, namely the closeness of the keywords within each category. And it indicates that this category maintains and develops its own capabilities [25]. The above eight categories were assigned to the four quadrants based on the results of the cluster analysis. In addition, excel was utilized to generate strategic diagram.

\section{Social network analysis}

The high frequency MeSH terms co-occurrence matrix was imported into the Ucinet 6.0 (Analytic Technologies Co., Lexington, KY, USA) software. And the social network analysis method was utilized to analyze the subject and knowledge structure of the application of stents in pancreatic diseases. Then the high-frequency MeSH term network was visualized by NetDraw 2.084 software. The nodes represent MeSH terms, and the links stand for the co-occurrence frequency of these terms. And we measured the degree, betweenness and closeness centralities of every node. At the same time, author relationship network was constructed by above methods.

\section{Results:}




\section{Overall evaluation}

Based on GoPubMed, we obtained the literature information according to the search strategy: stents [MeSH] and pancreas [MeSH] or "pancreatic diseases" [MeSH]. Figure 1A depicts the distribution of the publication year of corresponding papers. The first article was published in 1977. As time went by, the volume of publications increased year by year. By 2015, it had a downward trend. Figure 1B shows the volume of paper outputs concerning the application of stents in pancreatic diseases in first 20 countries. And the map was generated by an online website (pixelmap.amcharts.com). The number in the map is the quantity of associated publications for every country or region. The United States stands first with 1167 publications. Furthermore, we summarized the annual distribution of MeSH terms associated with the application of stents in pancreatic diseases (Figure 1C). Different colors represent different highly frequent major MeSH terms. We found that these MeSH terms had roughly the same development trend every year from 1985-2018, indicating that they had close associations. As shown in Table 1, the top 29 authors with a cumulative percentage of 27.9483 are listed. "Baron TH" (84, 2.0468\%), "Kahaleh M" $(81,1.9737 \%)$ and "Isayama H” $(65,1.5838 \%)$ are the top three authors. From 1977 to 2018, the 25 most active journals published publications on the application of stents in pancreatic diseases account for $49.92 \%$ of all publications. Table 2 demonstrates the 25 most productive journals, as the core journals in the research fields on the application of stents in pancreatic diseases under Bradford's Law. "Gastrointestinal endoscopy", "Endoscopy", "World journal of gastroenterology" are the most active three journals.

Figure 1. The information of literature on the application of stents in pancreatic diseases. A. The growth of literature publications about the application of stents in pancreatic diseases from 1977 to 2018; B. Geographic distribution of research outputs on the application of stents in pancreatic diseases; C. Annual distribution of MeSH terms about the application of stents in pancreatic diseases

Table 1. The 29 top authors from the listed publications on the application of stents in pancreatic diseases (PubMed sourced until May 2018)

Table 2. Most active journals on the topic of the application of stents in pancreatic diseases (PubMed sourced until May 2018)

High-frequent major MeSH terms

4087 articles were selected until May 15 th, 2018.83 high-frequency MeSH terms were extracted from the listed publications, with a cumulative percentage of 57.5291 (Table 3). "Stents" (2238, 3.8488\%), "Treatment Outcome" (1038, 1.7851\%) and "Retrospective Studies" $(758,1.3036 \%)$ are the top three MeSH terms.

Table 3. 83 high-frequent major MeSH terms from the listed publications on the application of stents in pancreatic diseases

\section{Cluster analysis}

The double cluster analysis results were visualized into mountain visualization and hierarchical cluster tree. In the mountain visualization, the peak and matrix visualizations express the high-frequency MeSH terms. Each cluster represents a peak marked by cluster number 0-7 in Figure 2, and the related clusters are described according to the volume, color and height of the 
197

198

199

200

201

202

203

204

205

206

207

208

209

210

211

212

213

214

215

216

217

218

219

220

221

222

223

224

225

226

227

228

229

230

231

232

233

234

235

236

237

peaks. The volume of the peak is directly proportional to the number of MeSH terms in the cluster. In the meanwhile, the internal standard deviation of a cluster object is represented by the color of the peak. Blue stands for the high deviation and red represents the low deviation. The peak is the position relative to the other clusters. The closer the distance between the two peaks, the higher the similarity between the two clusters. The height and similarity of each cluster are proportional to each other.

In Figure 3, the row labels represent high-frequency MeSH terms, and the PMIDs locate the column labels at the right and bottom of the matrix. The color of each grid suggests the frequency of appearance in a paper. The darker the red, the greater the frequency. 83 highfrequency major MeSH terms are distinguished into 8 clusters in matrix visualization. The top and left of hierarchical tree respectively indicate the relationships among the major MeSH terms and the associations among the papers. Meanwhile, the corresponding article is obviously shown for each high frequency MeSH terms in each cluster.

Figure 2. A mountain visualization biclustering of 83 high-frequent major MeSH terms and papers on the application of stents in pancreatic diseases

\section{Figure 3. A visualized matrix biclustering of highly frequent major MeSH terms and} PubMed Unique Identifiers (PMIDs) of articles on the application of stents in pancreatic diseases

\section{Strategic diagram}

The centrality and density of the 8 clusters are listed in Table 4. The details of MeSH terms and clusters are shown in Table 5. In Figure 4, x-axis represents the centrality, and y-axis stands for the density on the strategy diagram. The four quadrants clockwise from the upper right corner express the first quadrant, the second quadrant, the third quadrant and the fourth quadrant. As shown in Figure 4A, the clusters in the first quadrant are suggested to be central topics in the network (due to their strong connection with other clusters) and have intense internal relationships (due to high degree of development). The clusters in the second quadrant are peripheral, however, already well-developed topic. The clusters in the third quadrant are both peripheral and undeveloped. The clusters in the fourth quadrant are central and undeveloped, but they are becoming mature to some extent [26].

Figure 4B depicts that cluster 1 and cluster 3 are located in the first quadrant, suggesting that the cluster densities and centrality degrees are all high, that is to say, the MeSH terms in cluster 1 and cluster 3 are closely linked, and research tends to be well-developed. And the orientation is high, indicating that it is at the center of the research network. Cluster 4 and 7 are located in the second quadrant with high density and low centrality, indicating that internal links are close together with a clear topic. The research on this topic is shown to be relatively welldeveloped, with little correlation with other research. Cluster 0, 2 and 6 are located in the third quadrant, with low density and centrality. MeSH terms of Cluster 0, 2 and 6 are the margins of the entire field. The internal structure is relatively loose and research is yet developed. Cluster 5 is located in the fourth quadrant with low density and high centrality, indicating that it has close relations with other research. However, the research is not found to be well-developed. The research on this topic has potential value, and is now in the exploratory stage; however, more 
238

239

240

241

242

243

244

245

246

247

248

249

250

251

252

253

254

255

256

257

258

259

260

261

262

263

264

265

266

267

268

269

270

271

272

273

274

275

276

277

research is required.

Table 4. The centrality and density of the 8 clusters about the application of stents in pancreatic diseases

Table 5. The cluster analysis of 8 clusters the application of stents in pancreatic diseases.

Figure 4. Strategic diagram for the application of stents in pancreatic diseases. (A) The meaning of strategic diagram. (B) The strategic diagram of the 8 clusters for the application of stents in pancreatic diseases

Social network analysis

As shown in Figure 5A, we constructed the author relationship network. There are 29 nodes which represent 29 authors. The size and location of nodes suggests the decisive role of an author. Links indicate the connection between two authors. In Figure $\mathbf{5 A}$, the node "Itoi T" was the largest one, which was located in the center of the social network, followed by "Isayama H" and "Sasaki T". Therefore, these authors could play a critical role in the field of the application of stents in pancreatic diseases. Their articles could represent the maturity of the research area and hot spots. Figure 5B depicts that the network relationships among 83 high-frequent major $\mathrm{MeSH}$ terms. The size of nodes suggests the centrality of high-frequent major MeSH terms. In the meanwhile, the thickness of the lines demonstrates the co-occurrence frequency of keywords pairs.

Figure 5. Social network analysis. A. The top 29 author relationship network. The size and location of nodes represent the centrality of an author in the social network. B. The network of high-frequent major MeSH terms. Nodes suggest high-frequent major MeSH terms. The size and location of nodes represent the centrality of a MeSH term in the network structure map. Links stand for the connection between MeSH terms, and the number or thickness of the lines stands for the co-occurrence frequency of high-frequent major MeSH terms

\section{Discussion:}

We took advantage of GoPubMed to analyze the publication trends in the field of pancreatic stents. Before 2015, the volume of relevant publications was continuously rising and relative research interest was fluctuating rising. However, beginning with 2015, the volume of publications and relative research interest both showed a downward trend, which suggests that the researchers' interest have shifted and more innovation needs to be explored in the pancreatic stents. In addition, we also focused on the countries and author of research outputs. The United States, Japan and Germany remain to be the countries with the largest number of publications on pancreatic stents. The results indicated the developed countries occupied main position in the field. After measuring the top 29 authors on pancreatic stents, we made the author relationship network. The authors in the field have close cooperation, emphasizing the importance of cooperation. By paying attention to these authors, we would have a general understanding of the research direction and hotspots in this field. In order to further track research trends, journals are also the focus of attention. Therefore, we measured the most active journals, considering as the central journals in the relevant fields such as Gastrointestinal endoscopy, Endoscopy, World 
278 journal of gastroenterology. The high-frequency MeSH terms may reflect the research hot spots.

279 The 83 high-frequency major MeSH terms were achieved by the co-occurrence in the same

280 paper, which represented the research content in the field. Yearly distribution trends on different

$281 \mathrm{MeSH}$ terms had the same fluctuating trend.

28283 hot major MeSH terms were clustered into 8 clusters. The network revealed that these

$283 \mathrm{MeSH}$ terms existed complex relationship network. Endoscopic retrograde ERCP in acute and

284 chronic pancreatitis and imaging methods as an auxiliary method of stent placement are located

285 in the second quadrant. Cluster 1 and 3 are located in the first quadrant, including the

286 complications of stent placement in bile duct neoplasms and pancreatic neoplasms and stents for

287 the prevention of pancreatic fistula following pancreaticoduodenectomy. The two topics are

288 current research center and hot topics for pancreatic stents. And cluster 0, 2, 6 are located in the

289 third quadrant, which suggesting that the three topics are at the margin and not yet mature, including stents placement in pancreatic neoplasms, the postoperative complications after stent placement therapy such as pancreaticoduodenectomy and pancreatic ducts changes for patients in chronic pancreatitis. In the meanwhile, complications such as pancreatitis associated with stent implantation could have potential research value in the fourth quadrant, which are the research center, however, not yet mature. Therefore, the topic could become potential hotspots in the future science research. Then the 8 topics would be introduced respectively.

\section{Stents placement in pancreatic neoplasms}

Increasing numbers of patients with resectable pancreatic neoplasms are receiving neoadjuvant therapy such as stents placement. Tumor growth in pancreatic neoplasms often leads to invasion of other organs and biliary obstruction, resulting in repeated stent placement [27]. The self-expandable metal stents possess effectiveness and safety in achieving durable biliary drainage for patients with pancreatic neoplasms [28, 29]. For example, the covered selfexpanding metal stents is used for the therapy of biliary tract hemorrhage induced by advanced pancreatic cancer-induced portal biliary disease [30].

\section{The complications of stent placement in bile duct neoplasms and pancreatic neoplasms}

As for pancreatic neoplasms, preoperative biliary drainage (PBD) promotes complications compared with surgery without PBD. The result could be associated with the plastic stents utilized. However, metal stents might decrease the PBD-associated complications [31]. It has been confirmed that biliary stents could remarkably increase liver volume in both hilar and distal bile duct neoplasms [32]. Endoscopic retrograde biliary drainage of metal bile duct stents are widely used for biliary obstruction. The application of bile duct stents has also led to an increasing number of complications. The main complications of pancreatic stents include migration, stent occlusion, and pancreatic ductal changes [33].

\section{Postoperative complications after stent placement such as pancreaticoduodenectomy}

Pancreatic fistula is a leading complication following pancreaticoduodenectomy. Pessaux $\mathrm{P}$ et al. have reported that external pancreatic duct stent reduces pancreatic fistula rate following pancreaticoduodenectomy [34]. Obstructive jaundice is one of the known risk factors for treatment failure following hepatectomy for patients with hilar cholangiocarcinoma. In palliative care, self-expanding metal stents have a rapid reduction in bile duct pressure and reduce 
319 complication rates, while providing patients with adequate and rapid biliary drainage [35].

320

321

322

323

324

325

326

327

328

329

330

331

332

333

334

335

336

337

338

339

340

341

342

343

344

345

346

347

348

349

350

351

352

353

354

355

356

357

358

\section{Stents for the prevention of pancreatic fistula following pancreaticoduodenectomy}

It is necessary to prevent pancreatic fistula after pancreaticoduodenectomy in stent placement. The incidence of pancreatic fistula in patients undergoing pancreaticoduodenectomy is as high as $56 \%$ and is considered to be a main factor on morbidity and mortality in patients following pancreaticoduodenectomy [36, 37]. And external duct stents placement could reduce the occurrence for clinically relevant postoperative pancreatic fistula [38].

\section{Prophylactic pancreatic duct stent can reduce the incidence of post-ERCP pancreatitis} (PEP) and complications such as pancreatitis associated with stent implantation

Endoscopic retrograde ERCP was first introduced in 1968. As a diagnostic tool, it was used to assess the disorders of pancreas [39]. As a most common complication of ERCP, the incidence of PEP is still as high as $15 \%$ in high-risk cases [40]. And a small number of patients could develop severe pancreatitis. Pancreatitis is a common and serious complication for endoscopic retrograde ERCP. Prevention of pancreatitis after ERCP remains the focus of clinical and research. Relevant strategies could decrease the occurrence of post-ERCP pancreatitis including patient selection, risk stratification, surgical techniques, pancreatic stenting, and drug prophylaxis. Placement of the pancreatic stent is a relatively new and increasingly popular method of reducing the risk of pancreatitis after ERCP [41]. Prophylactic pancreatic stent placement decreases the incidence of pancreatitis after ERCP in high risk patients and reduces the severity of this condition [42]. In summary, placement for pancreatic duct stent decreases the incidence of pancreatitis [43].

\section{Pancreatic duct changes in patients with chronic pancreatitis}

It is essential to prevent pancreatic duct changes such as pancreatic leakage or pancreatic duct patency after pancreaticoduodenectomy. In duct-to-mucosa anastomosis, placement of the stent could be an effective mean of dilating the pancreatic duct [44]. Pancreatic stent is used to improve painful, obstructive chronic pancreatitis [45].

\section{Stent placement in endoscopic pancreatic pseudocyst drainage}

Pancreatic pseudocyst is one of the common local complications of acute and chronic pancreatitis. And endoscopic pancreatic pseudocyst drainage has been widely applied in the treatment of pancreatic pseudocysts [46]. Endoscopic drainage has the advantages of small invasiveness, short recovery time, low cost and low complication rate [47], like interventional endoscopic ultrasonography has been increasingly used to manage pseudocyst formation [48]. As an example, Varadarajulu $\mathrm{S}$ et al. have found that, compared with surgical bladder anastomosis, patients with endoscopy pancreatic pseudocyst drainage experience rarely recurrence of pseudocyst during follow-up [49].

\section{Conclusion:}

We analyzed the literature on pancreatic stents based on bibliometric analysis. Finally, 83 high-frequent $\mathrm{MeSH}$ terms and 8 topics were found. And we found how to reduce the incidence of postoperative complications and improve the prognosis of patients with pancreatic diseases by stent implantation is still the focus of future research. This conclusion could provide potential

Peer) reviewing PDF | (2019:03:36000:1:1:NEW 29 Jul 2019) 
359

360

361

362

363

364

365

366

367

368

369

370

371

372

373

374

375

376

377

378

379

380

381

382

383

384

385

386

387

388

389

390

391

392

393

394

395

396

and invaluable insight for researchers in the further research.

\section{Abbreviations:}

MeSH: Medical Subject Headings; BICOMB: Bibliographic Item Co-Occurrence Matrix Builder; PMIDs: PubMed Unique Identifiers; PBD: preoperative biliary drainage; ERCP: cholangiopancreatography.

\section{Acknowledgments: Not applicable.}

\section{References:}

[1] Briggs CD, Irving GR, Cresswell A, Peck R, Lee F, Peterson M, Cameron IC. Percutaneous transhepatic insertion of self-expanding short metal stents for biliary obstruction before resection of pancreatic or duodenal malignancy proves to be safe and effective. Surg Endosc. 2010, 24(3):567-71.

[2] Zhu HD, Guo JH, Huang M, Ji JS, Xu H, Lu J, Li HL, Wang WH, Li YL, Ni CF, Shi HB, Xiao EH, Lv WF, Sun JH, Xu K, Han GH, Du LA, Ren WX, Li MQ, Mao AW, Xiang H, Zhang KX, Min J, Zhu GY, Su C, Chen L, Teng GJ. Irradiation stents vs. conventional metal stents for unresectable malignant biliary obstruction: A multicenter trial. J Hepatol. 2018, 68(5):970-977. [3] Baron TH. Best endoscopic stents for the biliary tree and pancreas. Curr Opin Gastroenterol. 2014, 30(5):453-6.

[4] Torre LA, Bray F, Siegel RL, Ferlay J, Lortet-Tieulent J, Jemal A. Global cancer statistics, 2012. CA Cancer J Clin. 2015, 65(2):87-108.

[5] Siegel RL, Miller KD, Jemal A. Cancer statistics, 2018. CA Cancer J Clin. 2018, 68(1):7-30. [6] Haapamäki C, Kylänpää L, Udd M, Lindström O, Grönroos J, Saarela A, Mustonen H, Halttunen J. Randomized multicenter study of multiple plastic stents vs. covered self-expandable metallic stent in the treatment of biliary stricture in chronic pancreatitis. Endoscopy. 2015, 47(7):605-10.

[7] Su H, Lee P. Mapping knowledge structure by keyword co-occurrence: a first look at journal papers in Technology Foresight. Scientometrics 2010, 85(1):65-79.

[8] Thompson DF, Walker CK. A descriptive and historical review of bibliometrics with applications to medical sciences. Pharmacotherapy. 2015, 35(6):551-9.

[9] Yao Q, Chen K, Yao L, Lyu PH, Yang TA, Luo F, Chen SQ, He LY, Liu ZY. Scientometric trends and knowledge maps of global health systems research. Health Res Policy Syst. 2014, $12: 26$.

[10] Hong Y, Yao Q, Yang Y, Feng JJ, Wu SD, Ji WX, Yao L, Liu ZY. Knowledge structure and theme trends analysis on general practitioner research: a coword perspective. BMC Fam Pract. 2016, 17:10.

[11] Zhang Z, Murtagh F, Van Poucke S, Lin S, Lan P. Hierarchical cluster analysis in clinical research with heterogeneous study population: Highlighting its visualization with R. Ann Transl Med. 2017, 5(4): 75.

[12] Cheng Y, Church GM. Biclustering of expression data. Eighth International Conference on 
397

398

399

400

401

402

403

404

405

406

407

408

409

410

411

412

413

414

415

416

417

418

419

420

421

422

423

424

425

426

427

428

429

430

431

432

433

434

435

436

437

Intelligent Systems for Molecular Biology AAAI Press. 2000, 8: 93-103.

[13] Hartigan JA. Direct clustering of a data matrix. Publications of the American Statistical Association. 1978, 67(337): 123-29.

[14] Le NQK, Huynh TT, Yapp EKY, Yeh HY. Identification of clathrin proteins by incorporating hyperparameter optimization in deep learning and PSSM profiles. Computer Methods and Programs in Biomedicine. 2019, 177: 81-88.

[15] Le NQ. iN6-methylat (5-step): identifying DNA N6-methyladenine sites in rice genome using continuous bag of nucleobases via Chou's 5-step rule. Molecular Genetics and Genomics. 2019.

[16] Doms A, Schroeder M. GoPubMed: exploring PubMed with the Gene Ontology. Nucleic Acids Res. 2005, 33:W783-6.

[17] Mandrekar JN. Measures of interrater agreement. J Thorac Oncol. 2011, 6(1):6-7.

[18] T. Dehdarirad, A. Villarroya, M. Barrios. Research trends in gender differences in higher education and science: a co-word analysis, Scientometrics. 2014, 101: 273-290.

[19] J. Hu, Y. Zhang. Research patterns and trends of Recommendation System in China using co-word analysis. Information Processing \& Management. 2015, 51: 329-33.

[20] Cui Lei, Liu Wei, Yan Lei, Zhang Han, Hou Yuefang, Huang Yingna, Zhang Hao.

Development of a text mining system based on the co-occurrence of bibliographic items in literature. New Technology of Library and Information Service. 2008, (8):70-75.

[21] Le NQ, Ou YY. Prediction of FAD binding sites in electron transport proteins according to efficient radial basis function networks and significant amino acid pairs. BMC Bioinformatics. 2016, 17:298.

[22] Le NQ, Ho QT, Ou YY. Using two-dimensional convolutional neural networks for identifying GTP binding sites in Rab proteins. J Bioinform Comput Biol. 2019, 17(1):1950005. [23] Karypis Lab. Webcite gCLUTO-Graphical Clustering Toolkit. 2014.

[24] Li F, Li M, Guan P, Ma S, Cui L. Mapping publication trends and identifying hot spots of research on Internet health information seeking behavior: a quantitative and co-word biclustering analysis. J Med Internet Res. 2015, 17(3):e81.

[25] Callon M, Courtial J P, Laville F. Co-word analysis as a tool for describing the network of interactions between basic and technology research: the case of polymer chemistry.

Scientometrics. 1991, 22(1): 155-205.

[26] Indolfi L, Ligorio M2 Ting DT, Xega K, Tzafriri AR, Bersani F, Aceto N, Thapar V, Fuchs BC, Deshpande V, Baker AB, Ferrone CR, Haber DA, Langer R, Clark JW, Edelman ER. A tunable delivery platform to provide local chemotherapy for pancreatic ductal adenocarcinoma. Biomaterials. 2016, 93:71-82.

[27] Shi B, Wei W, Qin X, Zhao F, Duan Y, Sun W, Li D, Cao Y. Mapping theme trends and knowledge structure on adipose-derived stem cells: a bibliometric analysis from 2003 to 2017.

Regen Med. 2019, 14(1):33-48.

[28] Aadam AA, Evans DB, Khan A, Oh Y, Dua K. Efficacy and safety of self-expandable metal stents for biliary decompression in patients receiving neoadjuvant therapy for pancreatic cancer: a prospective study. Gastrointest Endosc. 2012, 76(1):67-75. 
438 [29] van der Horst A, Lens E, Wognum S, de Jong R, van Hooft JE, van Tienhoven G, Bel A.

439 Limited role for biliary stent as surrogate fiducial marker in pancreatic cancer: stent and

440 intratumoral fiducials compared. Int J Radiat Oncol Biol Phys. 2014, 89(3):641-8.

441 [30] Kim SY, Cho JH, Kim EJ, Choi SJ, Kim YS. Successful hemostasis using a covered self-

442 expandable metallic stent for spurting hemobilia in patients with advanced pancreatic cancer-

443 induced portal biliopathy. Gastrointest Endosc. 2016, 84(5):858-860.

444 [31] Tol JA, van Hooft JE, Timmer R, Kubben FJ, van der Harst E, de Hingh IH, Vleggaar FP,

445 Molenaar IQ, Keulemans YC, Boerma D, Bruno MJ, Schoon EJ, van der Gaag NA, Besselink

446 MG, Fockens P, van Gulik TM, Rauws EA, Busch OR, Gouma DJ. Metal or plastic stents for

447 preoperative biliary drainage in resectable pancreatic cancer. Gut. 2016, 65(12):1981-1987.

448 [32] Lee CH, Kim SH, Kim IH, Kim SW, Lee ST, Kim DG, Yang JD, Yu HC, Cho BH, Lee SO.

449 Endoscopic stenting in bile duct cancer increases liver volume. Gastrointest Endosc. 2014,

450 80(3):447-55.

451 [33] ASGE Technology Assessment Committee, Pfau PR, Pleskow DK, Banerjee S, Barth BA, 452 Bhat YM, Desilets DJ, Gottlieb KT, Maple JT, Siddiqui UD, Tokar JL, Wang A, Song LM,

453 Rodriguez SA. Pancreatic and biliary stents. Gastrointest Endosc. 2013, 77(3):319-27.

454 [34] Pessaux P, Sauvanet A, Mariette C, Paye F, Muscari F, Cunha AS, Sastre B, Arnaud JP;

455 Fédération de Recherche en Chirurgie (French). External pancreatic duct stent decreases

456 pancreatic fistula rate after pancreaticoduodenectomy: prospective multicenter randomized trial.

457 Ann Surg. 2011, 253(5):879-85.

458 [35] Grünhagen DJ, Dunne DF, Sturgess RP, Stern N, Hood S, Fenwick SW, Poston GJ, Malik

459 HZ. Metal stents: a bridge to surgery in hilar cholangiocarcinoma. HPB (Oxford). 2013,

460 15(5):372-8.

461 [36] Dong Z, Xu J, Wang Z, Petrov MS. Stents for the prevention of pancreatic fistula following 462 pancreaticoduodenectomy. Cochrane Database Syst Rev. 2016, (5):CD008914.

463 [37] Brown EG, Yang A, Canter RJ, Bold RJ. Outcomes of pancreaticoduodenectomy: where 464 should we focus our efforts on improving outcomes? JAMA Surgery 2014, 147 (7):694-9.

465 [38] Motoi F, Egawa S, Rikiyama T, Katayose Y, Unno M. Randomized clinical trial of external 466 stent drainage of the pancreatic duct to reduce postoperative pancreatic fistula after

467 pancreaticojejunostomy. Br J Surg. 2012, 99(4):524-31.

468 [39] Riff BP, Chandrasekhara V. The Role of Endoscopic Retrograde Cholangiopancreatography

469 in Management of Pancreatic Diseases. Gastroenterol Clin North Am. 2016, 45(1):45-65.

470 [40] Elmunzer BJ. Reducing the risk of post-endoscopic retrograde cholangiopancreatography

471 pancreatitis. Dig Endosc. 2017, 29(7):749-757.

472 [41] Shi QQ, Ning XY, Zhan LL, Tang GD, Lv XP. Placement of prophylactic pancreatic stents

473 to prevent post-endoscopic retrograde cholangiopancreatography pancreatitis in high-risk

474 patients: a meta-analysis. World J Gastroenterol. 2014, 20(22):7040-8.

475 [42] Freeman ML. Pancreatic stents for prevention of post-endoscopic retrograde

476 cholangiopancreatography pancreatitis. Clin Gastroenterol Hepatol. 2007, 5(11):1354-65.

477 [43] Sofuni A, Maguchi H, Mukai T, Kawakami H, Irisawa A, Kubota K, Okaniwa S, Kikuyama

478 M, Kutsumi H, Hanada K, Ueki T, Itoi T. Endoscopic pancreatic duct stents reduce the incidence 
479 of post-endoscopic retrograde cholangiopancreatography pancreatitis in high-risk patients. Clin 480 Gastroenterol Hepatol. 2011, 9(10):851-8.

481 [44] Téllez-Aviña FI, Casasola-Sánchez LE, Ramírez-Luna MÁ, Saúl Á, Murcio-Pérez E, Chan 482 C, Uscanga L, Duarte-Medrano G, Valdovinos-Andraca F. Permanent Indwelling Transmural 483 Stents for Endoscopic Treatment of Patients With Disconnected Pancreatic Duct Syndrome:

484 Long-term Results. J Clin Gastroenterol. 201, 52(1):85-90.

485 [45] Samuelson A, Zeligman B, Russ P, Austin GL, Yen R, Shah RJ. Pancreatic Duct Changes in 486 Patients with Chronic Pancreatitis Treated With Polyethylene and Sof-Flex Material Stents: A 487 Blinded Comparison. Pancreas. 2016, 45(2):281-5.

488 [46] Madder RD, Khan M, Husaini M, Chi M, Dionne S, VanOosterhout S, Borgman A, Collins 489 JS, Jacoby M. Combined Near-Infrared Spectroscopy and Intravascular Ultrasound Imaging of 490 Pre-Existing Coronary Artery Stents: Can Near-Infrared Spectroscopy Reliably Detect 491 Neoatherosclerosis? Circ Cardiovasc Imaging. 2016, 9(1): e003576.

492 [47] Shah RJ, Shah JN, Waxman I, Kowalski TE, Sanchez-Yague A, Nieto J, Brauer BC, 493 Gaidhane M, Kahaleh M. Safety and efficacy of endoscopic ultrasound-guided drainage of 494 pancreatic fluid collections with lumen-apposing covered self-expanding metal stents. Clin 495 Gastroenterol Hepatol. 2015, 13(4):747-52.

496 [48] Vilmann AS, Menachery J, Tang SJ, Srinivasan I, Vilmann P. Endosonography guided 497 management of pancreatic fluid collections. World J Gastroenterology. 2015, 21(41):11842-53.

498 [49] Varadarajulu S, Bang JY, Sutton BS, Trevino JM, Christein JD, Wilcox CM. Equal efficacy 499 of endoscopic and surgical cystogastrostomy for pancreatic pseudocyst drainage in a randomized 500 trial. Gastroenterology. 2013, 145(3):583-90.

\section{Figure legends:}

502 Figure 1. The information of literature on the application of stents in pancreatic diseases. A. The 503 growth of literature publications about the application of stents in pancreatic diseases from 1977 504 to 2018; B. Geographic distribution of research outputs on the application of stents in pancreatic 505 diseases; C. Annual distribution of MeSH terms about the application of stents in pancreatic 506 diseases.

507 Figure 2. A mountain visualization biclustering of 83 high-frequent major MeSH terms and 508 papers on the application of stents in pancreatic diseases.

509 Figure 3. A visualized matrix biclustering of highly frequent major MeSH terms and PubMed 510 Unique Identifiers (PMIDs) of articles on the application of stents in pancreatic diseases.

511 Figure 4. Strategic diagram for the application of stents in pancreatic diseases. (A) The meaning 512 of strategic diagram. (B) The strategic diagram of the 8 clusters for the application of stents in 513 pancreatic diseases.

514 Figure 5. Social network analysis. A. The top 29 author relationship network. The size and 515 location of nodes represent the centrality of an author in the social network. B. The network of 516 high-frequent major MeSH terms. Nodes suggest high-frequent major MeSH terms. The size and 517 location of nodes represent the centrality of a MeSH term in the network structure map. Links 518 stand for the connection between MeSH terms, and the number or thickness of the lines stands 
519 for the co-occurrence frequency of high-frequent major MeSH terms.

520 Table 1. The 29 top authors from the listed publications on the application of stents in pancreatic

521 diseases (PubMed sourced until May 2018).

522 Table 2. Most active journals on the topic of the application of stents in pancreatic diseases

523 (PubMed sourced until May 2018).

524 Table 3. 83 high-frequent major MeSH terms from the listed publications on the application of

525 stents in pancreatic diseases.

526 Table 4. The centrality and density of the 8 clusters about the application of stents in pancreatic

527 diseases.

528 Table 5. The cluster analysis of 8 clusters the application of stents in pancreatic diseases. 
Figure 1

The information of literature on the application of stents in pancreatic diseases.

A. The growth of literature publications about the application of stents in pancreatic diseases from 1977 to 2018; B. Geographic distribution of research outputs on the application of stents in pancreatic diseases; C. Annual distribution of MeSH terms about the application of stents in pancreatic diseases.
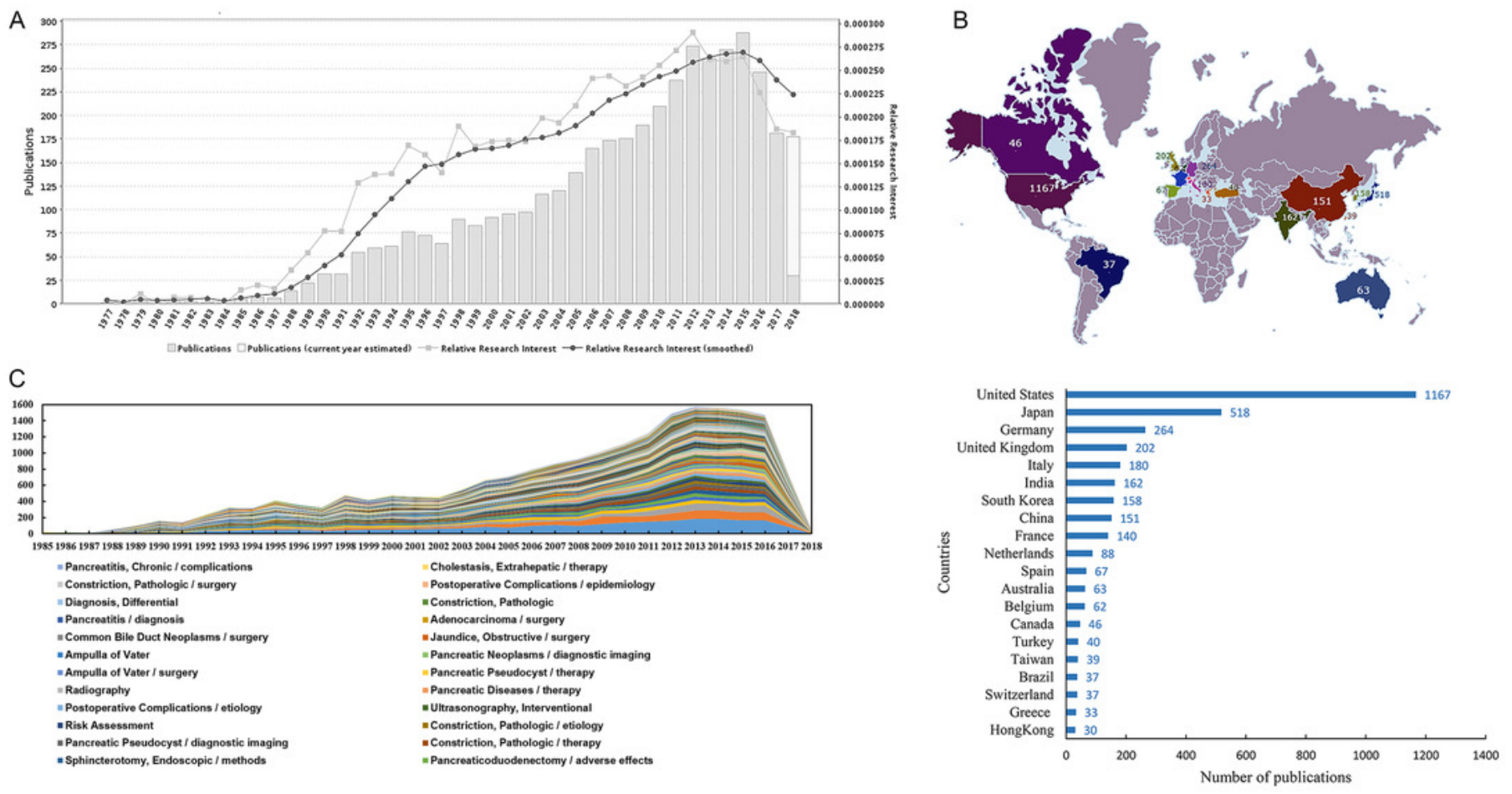
Figure 2

A mountain visualization biclustering of 83 high-frequent major MeSH terms and papers on the application of stents in pancreatic diseases. 


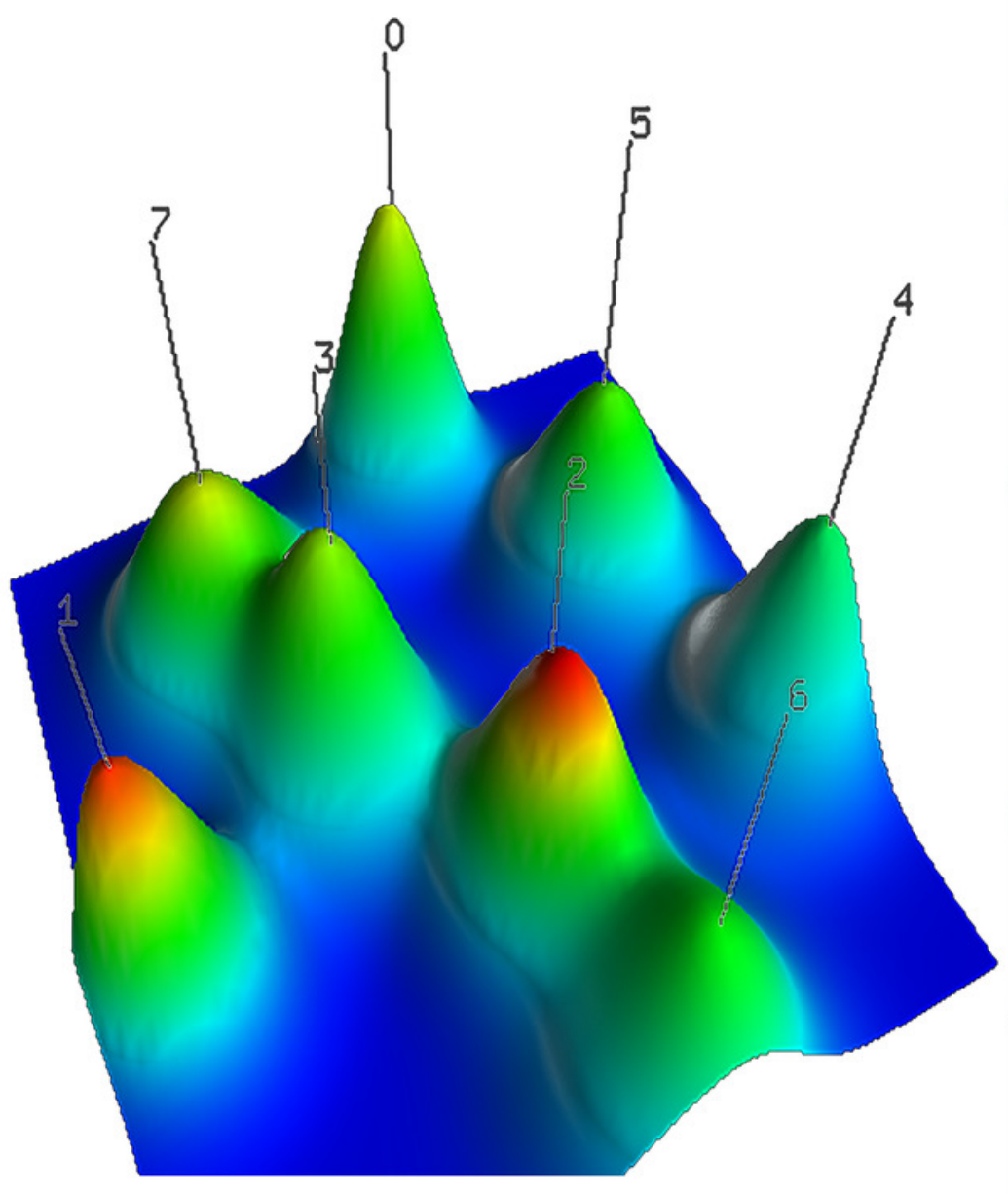

\begin{tabular}{|c|c|}
\hline Sluster & MeSH Terms \\
\hline \multirow[t]{8}{*}{0} & Pancreatic Neoplasms / pathology \\
\hline & Pancreatic Neoplasms / therapy \\
\hline & Pancreatic Neoplasms / diagnosis \\
\hline & Cholestasis, Extrahepatic / etiology \\
\hline & Radiography \\
\hline & Pancreatic Neoplasms / diagnostic imaging \\
\hline & Diagnosis, Differential \\
\hline & Cholestasis, Extrahepatic / therapy \\
\hline \multirow[t]{11}{*}{1} & Pancreatic Neoplasms / complications \\
\hline & Stents / adverse effects \\
\hline & Cholestasis / etiology \\
\hline & Palliative Care \\
\hline & Cholestasis / therapy \\
\hline & Cholestasis / surgery \\
\hline & Metals \\
\hline & Prosthesis Design \\
\hline & Equipment Design \\
\hline & Palliative Care / methods \\
\hline & Bile Duct Neoplasms / complications \\
\hline \multirow[t]{12}{*}{2} & Pancreatic Neoplasms / surgery \\
\hline & Jaundice, Obstructive / etiology \\
\hline & Survival Rate \\
\hline & Pancreaticoduodenectomy \\
\hline & Pancreatic Neoplasms / mortality \\
\hline & Postoperative Complications \\
\hline & Prognosis \\
\hline & Ampulla of Vater / surgery \\
\hline & Ampulla of Vater \\
\hline & Jaundice, Obstructive / surgery \\
\hline & Common Bile Duct Neoplasms / surgery \\
\hline & Adenocarcinoma / surgery \\
\hline \multirow[t]{14}{*}{3} & Stents \\
\hline & Treatment Outcome \\
\hline & Retrospective Studies \\
\hline & Follow-Up Studies \\
\hline & Tomography, X-Ray Computed \\
\hline & Prospective Studies \\
\hline & Time Factors \\
\hline & Drainage \\
\hline & Pancreas / surgery \\
\hline & Pancreatic Diseases / surgery \\
\hline & Pancreatic Fistula / etiology \\
\hline & Pancreaticoduodenectomy / adverse effects \\
\hline & Postoperative Complications / etiology \\
\hline & Postoperative Complications / epidemiology \\
\hline \multirow[t]{9}{*}{4} & Pancreatitis / etiology \\
\hline & Cholangiopancreatography, Endoscopic Retrograde / adverse effects \\
\hline & Cholangiopancreatography, Endoscopic Retrograde / methods \\
\hline & Risk Factors \\
\hline & Pancreatic Ducts \\
\hline & Pancreatitis / prevention \& control \\
\hline & Cholangiopancreatography, Endoscopic Retrograde / instrumentation \\
\hline & Sphincterotomy, Endoscopic / methods \\
\hline & Risk Assessment \\
\hline \multirow[t]{10}{*}{5} & Cholangiopancreatography, Endoscopic Retrograde \\
\hline & Chronic Disease \\
\hline & Sphincterotomy, Endoscopic \\
\hline & Recurrence \\
\hline & Pancreatitis / complications \\
\hline & Pancreatitis / surgery \\
\hline & Acute Disease \\
\hline & Pancreatitis / therapy \\
\hline & Endoscopy \\
\hline & Pancreatitis / diagnosis \\
\hline 6 & Pancreatic Ducts / surgery \\
\hline & Endoscopy, Digestive System \\
\hline & Pancreatic Ducts / pathology \\
\hline & Pancreatic Ducts / diagnostic imaging \\
\hline & Constriction, Pathologic / therapy \\
\hline & Constriction, Pathologic / etiology \\
\hline & Pancreatic Diseases / therapy \\
\hline & Constriction, Pathologic \\
\hline & Constriction, Pathologic / surgery \\
\hline & Pancreatitis, Chronic / complications \\
\hline 7 & Drainage / methods \\
\hline & Endosonography \\
\hline & Drainage / instrumentation \\
\hline & Pancreatic Pseudocyst / surgery \\
\hline & Endoscopy, Digestive System / methods \\
\hline & Endosonography/methods \\
\hline & Pancreatic Pseudocyst / diagnostic imaging \\
\hline & Ultrasonography, Interventional \\
\hline & Pancreatic Pseudocyst / therapy \\
\hline
\end{tabular}




\section{Figure 3}

A visualized matrix biclustering of highly frequent major MeSH terms and PubMed Unique Identifiers (PMIDs) of articles on the application of stents in pancreatic diseases.

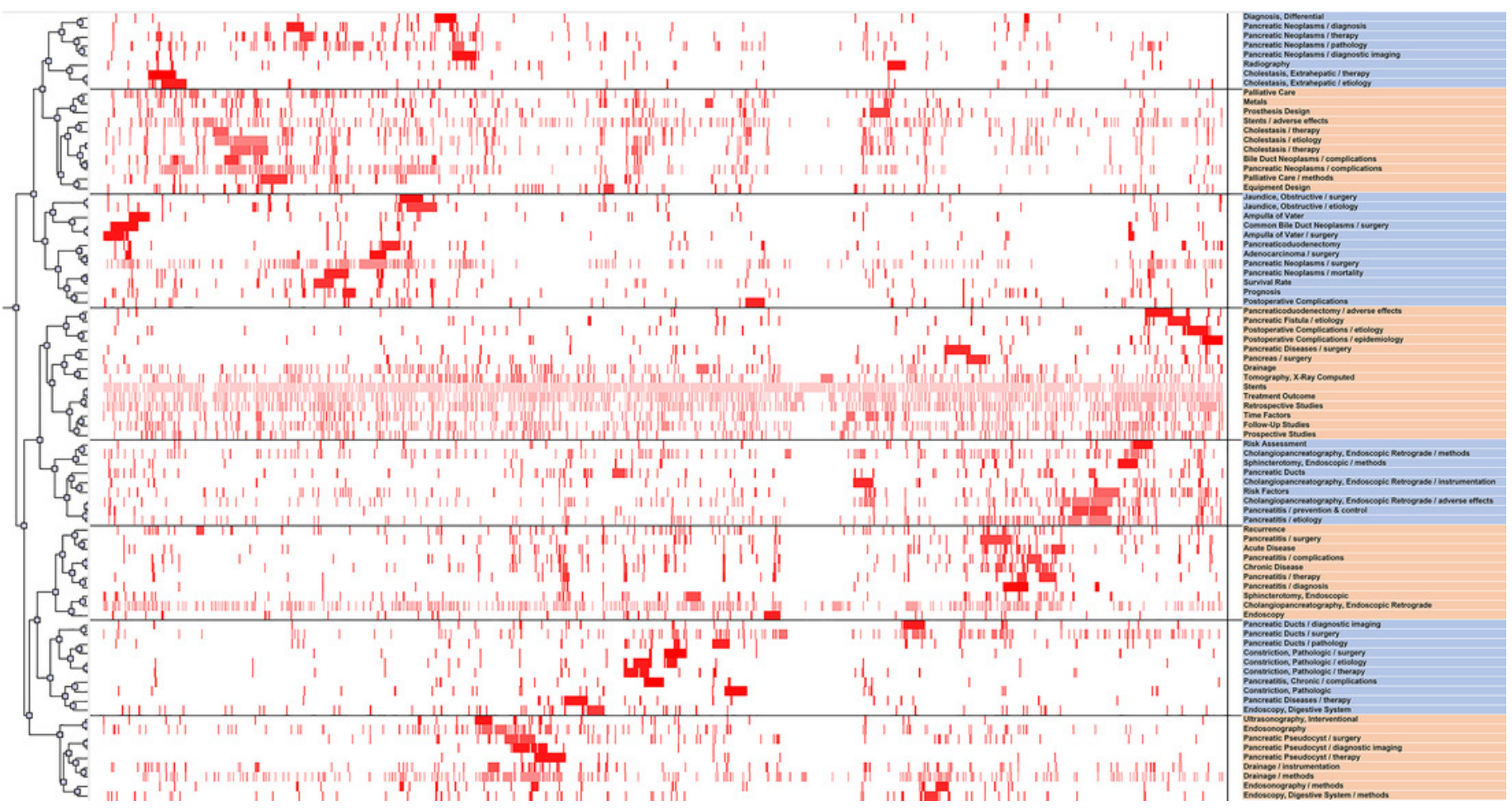


Figure 4

Strategic diagram for the application of stents in pancreatic diseases.

(A) The meaning of strategic diagram. (B) The strategic diagram of the 8 clusters for the application of stents in pancreatic diseases.

A

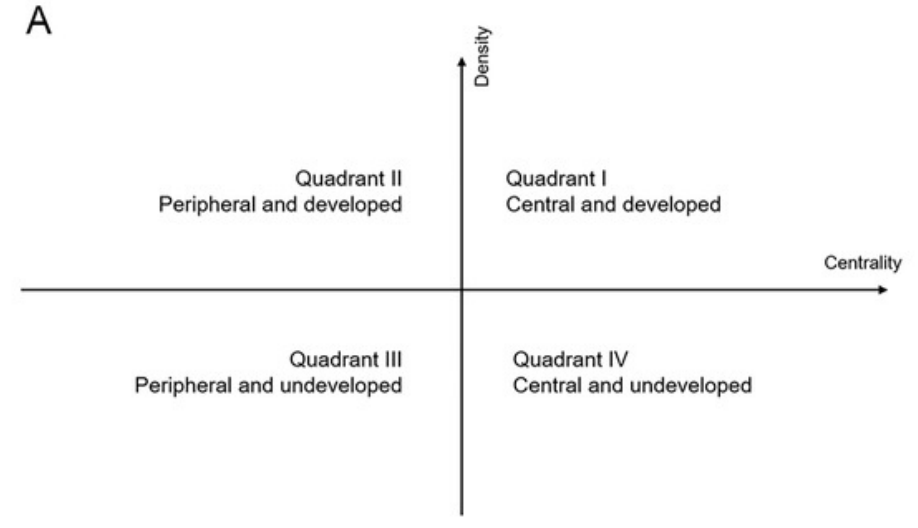

B

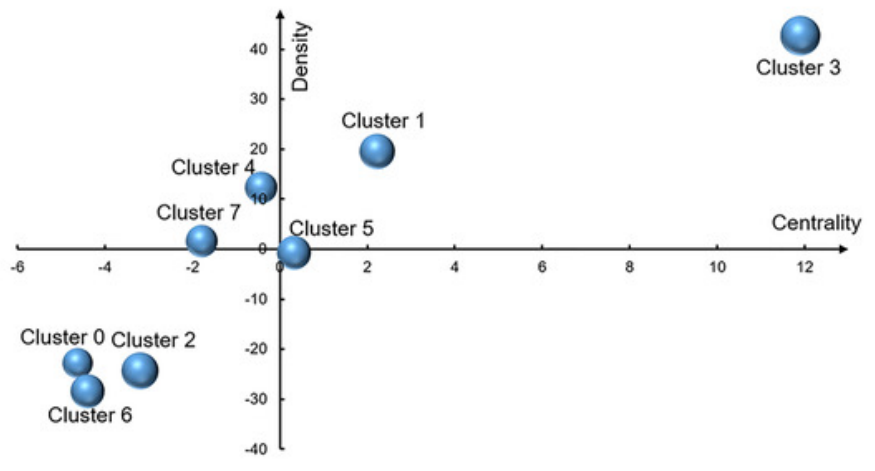




\section{Figure 5}

Social network analysis.

A. The top 29 author relationship network. The size and location of nodes represent the centrality of an author in the social network. B. The network of high-frequent major MeSH terms. Nodes suggest high-frequent major MeSH terms. The size and location of nodes represent the centrality of a MeSH term in the network structure map. Links stand for the connection between MeSH terms, and the number or thickness of the lines stands for the cooccurrence frequency of high-frequent major MeSH terms.
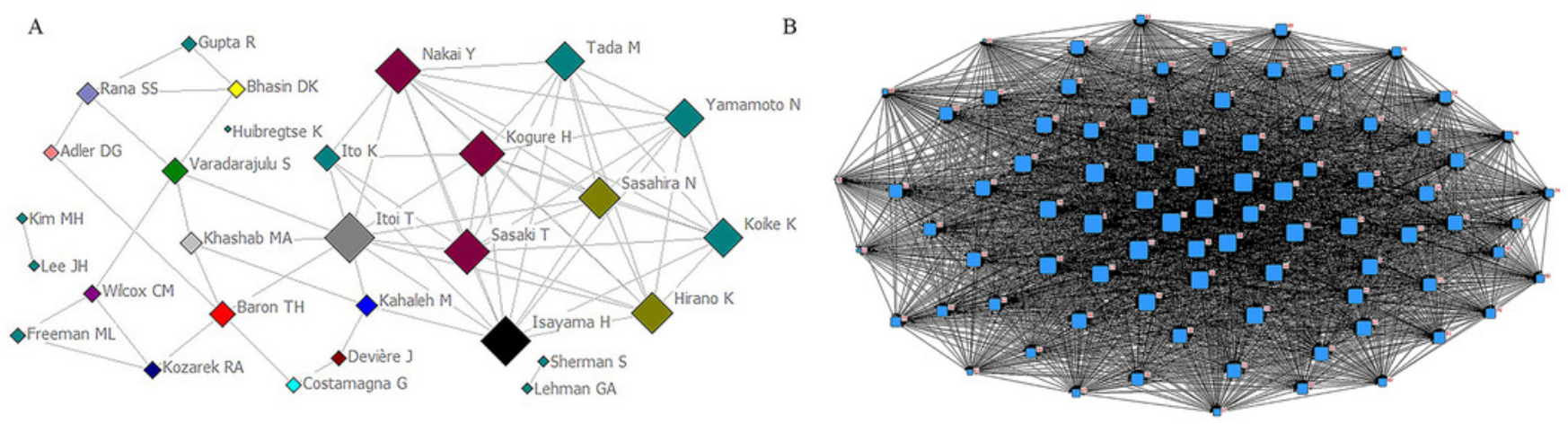


\section{Table $\mathbf{1}$ (on next page)}

The 29 top authors from the listed publications on the application of stents in pancreatic diseases (PubMed sourced until May 2018). 
1 Table 1. The 29 top authors from the listed publications on the application of stents in pancreatic 2 diseases (PubMed sourced until May 2018)

\begin{tabular}{|c|c|c|c|c|}
\hline No. & Author & Frequency & Percentage, $\%^{\mathrm{a}}$ & Cumulative percentage, $\%$ \\
\hline 1 & Baron TH & 84 & 2.0468 & 2.0468 \\
\hline 2 & Kahaleh M & 81 & 1.9737 & 4.0205 \\
\hline 3 & Isayama $\mathrm{H}$ & 65 & 1.5838 & 5.6043 \\
\hline 4 & Itoi $\mathrm{T}$ & 58 & 1.4133 & 7.0175 \\
\hline 5 & Nakai Y & 50 & 1.2183 & 8.2359 \\
\hline 6 & Varadarajulu S & 49 & 1.194 & 9.4298 \\
\hline 7 & Sherman S & 46 & 1.1209 & 10.5507 \\
\hline 8 & Lehman GA & 41 & 0.999 & 11.5497 \\
\hline 9 & Costamagna $\mathrm{G}$ & 39 & 0.9503 & 12.5 \\
\hline 10 & Tada M & 39 & 0.9503 & 13.4503 \\
\hline 11 & Bhasin DK & 38 & 0.9259 & 14.3762 \\
\hline 12 & Koike K & 37 & 0.9016 & 15.2778 \\
\hline 13 & Rana SS & 37 & 0.9016 & 16.1793 \\
\hline 14 & Devière J & 36 & 0.8772 & 17.0565 \\
\hline 15 & Freeman ML & 36 & 0.8772 & 17.9337 \\
\hline 16 & Kogure H & 36 & 0.8772 & 18.8109 \\
\hline 17 & Kozarek RA & 35 & 0.8528 & 19.6637 \\
\hline 18 & Hirano $\mathrm{K}$ & 32 & 0.7797 & 20.4435 \\
\hline 19 & Ito $\mathrm{K}$ & 31 & 0.7554 & 21.1988 \\
\hline 20 & Wilcox CM & 31 & 0.7554 & 21.9542 \\
\hline 21 & Sasahira N & 31 & 0.7554 & 22.7096 \\
\hline 22 & Sasaki T & 30 & 0.731 & 23.4405 \\
\hline 23 & Huibregtse K & 27 & 0.6579 & 24.0984 \\
\hline 24 & Kim MH & 27 & 0.6579 & 24.7563 \\
\hline 25 & Yamamoto N & 27 & 0.6579 & 25.4142 \\
\hline 26 & Khashab MA & 26 & 0.6335 & 26.0478 \\
\hline 27 & Lee JH & 26 & 0.6335 & 26.6813 \\
\hline 28 & Gupta R & 26 & 0.6335 & 27.3148 \\
\hline \multirow[t]{2}{*}{29} & Adler DG & 26 & 0.6335 & 27.9483 \\
\hline & Total & 1147 & & \\
\hline
\end{tabular}

3 aProportion of the frequency among 1147 times' appearance. 


\section{Table 2 (on next page)}

Most active journals on the topic of the application of stents in pancreatic diseases (PubMed sourced until May 2018). 
1 Table 2. Most active journals on the topic of the application of stents in pancreatic diseases 2 (PubMed sourced until May 2018)

\begin{tabular}{|c|c|c|}
\hline No. & Top journals & Publications n $(\%)$ \\
\hline 1 & Gastrointestinal endoscopy & $517(12.55)$ \\
\hline 2 & Endoscopy & $339(8.23)$ \\
\hline 3 & World journal of gastroenterology & $107(2.60)$ \\
\hline 4 & Surgical endoscopy & $101(2.45)$ \\
\hline 5 & $\begin{array}{l}\text { Digestive endoscopy : official journal of the Japan Gastroenterological Endoscopy } \\
\text { Society }\end{array}$ & $87(2.11)$ \\
\hline 6 & The American journal of gastroenterology & $76(1.85)$ \\
\hline 7 & Hepato-gastroenterology & $76(1.85)$ \\
\hline 8 & Cardiovascular and interventional radiology & $61(1.48)$ \\
\hline 9 & Gastrointestinal endoscopy clinics of North America & $61(1.48)$ \\
\hline 10 & Digestive diseases and sciences & $59(1.43)$ \\
\hline 11 & JOP : Journal of the pancreas & $51(1.24)$ \\
\hline 12 & Journal of gastroenterology and hepatology & $51(1.24)$ \\
\hline 13 & Journal of vascular and interventional radiology : JVIR & $48(1.17)$ \\
\hline 14 & $\begin{array}{l}\text { Journal of gastrointestinal surgery : official journal of the Society for Surgery of the } \\
\text { Alimentary Tract }\end{array}$ & $45(1.09)$ \\
\hline 15 & Journal of clinical gastroenterology & $45(1.09)$ \\
\hline 16 & Pancreas & $44(1.07)$ \\
\hline 17 & $\begin{array}{l}\text { Pancreatology: official journal of the International Association of Pancreatology (IAP) } \\
\ldots \text { [et al.] }\end{array}$ & $40(0.97)$ \\
\hline 18 & World journal of gastrointestinal endoscopy & $35(0.85)$ \\
\hline 19 & $\begin{array}{l}\text { Clinical gastroenterology and hepatology : the official clinical practice journal of the } \\
\text { American Gastroenterological Association }\end{array}$ & $33(0.80)$ \\
\hline 20 & Gut & $33(0.80)$ \\
\hline 21 & Endoscopic ultrasound & $32(0.78)$ \\
\hline 22 & HPB : the official journal of the International Hepato Pancreato Biliary Association & $30(0.73)$ \\
\hline 23 & Gan to kagaku ryoho. Cancer \& chemotherapy & $29(0.70)$ \\
\hline 24 & Journal of hepato-biliary-pancreatic sciences & $29(0.70)$ \\
\hline \multirow[t]{2}{*}{25} & Annals of surgery & $27(0.66)$ \\
\hline & Total & $2056(49.92)$ \\
\hline
\end{tabular}




\section{Table 3(on next page)}

83 high-frequent major MeSH terms from the listed publications on the application of stents in pancreatic diseases. 
1 Table 3. 83 High-frequent major MeSH terms from the listed publications on the application of 2 stents in pancreatic diseases

\begin{tabular}{|c|c|c|c|c|}
\hline No. & Major MeSHa terms/ MeSH subheadings & Frequency, $\mathrm{n}$ & Percentage, $\%$ b & $\begin{array}{l}\text { Cumulative } \\
\text { percentage, } \%\end{array}$ \\
\hline 1 & Stents & 2238 & 3.8488 & 13.9489 \\
\hline 2 & Treatment Outcome & 1038 & 1.7851 & 27.731 \\
\hline 3 & Retrospective Studies & 758 & 1.3036 & 30.3725 \\
\hline 4 & Cholangiopancreatography, Endoscopic Retrograde & 677 & 1.1643 & 31.5368 \\
\hline 5 & Pancreatic Neoplasms / complications & 544 & 0.9355 & 32.4723 \\
\hline 6 & Follow-Up Studies & 472 & 0.8117 & 33.284 \\
\hline 7 & Drainage / methods & 452 & 0.7773 & 34.0614 \\
\hline 8 & Pancreatic Neoplasms / surgery & 449 & 0.7722 & 34.8335 \\
\hline 9 & Stents / adverse effects & 401 & 0.6896 & 35.5231 \\
\hline 10 & Cholestasis / etiology & 379 & 0.6518 & 36.1749 \\
\hline 11 & Tomography, X-Ray Computed & 371 & 0.638 & 36.813 \\
\hline 12 & Pancreatitis / etiology & 338 & 0.5813 & 37.3942 \\
\hline 13 & $\begin{array}{l}\text { Cholangiopancreatography, Endoscopic Retrograde / } \\
\text { adverse effects }\end{array}$ & 335 & 0.5761 & 37.9704 \\
\hline 14 & $\begin{array}{l}\text { Cholangiopancreatography, Endoscopic Retrograde / } \\
\text { methods }\end{array}$ & 314 & 0.54 & 38.5104 \\
\hline 15 & Prospective Studies & 297 & 0.5108 & 39.0211 \\
\hline 16 & Pancreatic Ducts / surgery & 295 & 0.5073 & 39.5284 \\
\hline 17 & Time Factors & 289 & 0.497 & 40.0255 \\
\hline 18 & Drainage & 281 & 0.4832 & 40.5087 \\
\hline 19 & Palliative Care & 270 & 0.4643 & 40.973 \\
\hline 20 & Endosonography & 254 & 0.4368 & 41.4099 \\
\hline 21 & Cholestasis / therapy & 250 & 0.4299 & 42.2766 \\
\hline 22 & Risk Factors & 244 & 0.4196 & 42.6962 \\
\hline 23 & Pancreatic Neoplasms / pathology & 238 & 0.4093 & 43.1055 \\
\hline 24 & Cholestasis / surgery & 226 & 0.3887 & 43.4942 \\
\hline 25 & Chronic Disease & 198 & 0.3405 & 43.8347 \\
\hline 26 & Drainage / instrumentation & 195 & 0.3354 & 44.17 \\
\hline 27 & Metals & 185 & 0.3182 & 44.4882 \\
\hline 28 & Pancreatic Ducts & 184 & 0.3164 & 44.8046 \\
\hline 29 & Sphincterotomy, Endoscopic & 182 & 0.313 & 45.1176 \\
\hline 30 & Pancreatic Pseudocyst / surgery & 182 & 0.313 & 45.4306 \\
\hline 31 & Recurrence & 179 & 0.3078 & 45.7385 \\
\hline 32 & Pancreatitis / complications & 177 & 0.3044 & 46.0429 \\
\hline 33 & Pancreatitis / surgery & 176 & 0.3027 & 46.3455 \\
\hline 34 & Pancreatic Neoplasms / therapy & 169 & 0.2906 & 46.6362 \\
\hline 35 & Jaundice, Obstructive / etiology & 164 & 0.282 & 46.9182 \\
\hline
\end{tabular}


36 Prosthesis Design

37 Pancreatitis / prevention \& control

38 Acute Disease

39 Equipment Design

40 Palliative Care / methods

41 Bile Duct Neoplasms / complications

42 Pancreatitis / therapy

43 Endoscopy, Digestive System

44 Endoscopy, Digestive System / methods

45 Survival Rate

46 Pancreas / surgery

47 Pancreatic Diseases / surgery

Cholangiopancreatography, Endoscopic Retrograde / instrumentation

49 Pancreaticoduodenectomy

50 Pancreatic Neoplasms / mortality

51 Pancreatic Fistula / etiology

52 Postoperative Complications

53 Endosonography / methods

54 Prognosis

55 Pancreatic Ducts / pathology

56 Pancreatic Neoplasms / diagnosis

57 Endoscopy

58 Cholestasis, Extrahepatic / etiology

59 Pancreatic Ducts / diagnostic imaging

60 Pancreaticoduodenectomy / adverse effects

61 Sphincterotomy, Endoscopic / methods

62 Constriction, Pathologic / therapy

63 Pancreatic Pseudocyst / diagnostic imaging

64 Constriction, Pathologic / etiology

65 Risk Assessment

66 Ultrasonography, Interventional

67 Postoperative Complications / etiology

68 Pancreatic Diseases / therapy

69 Radiography

70 Pancreatic Pseudocyst / therapy

71 Ampulla of Vater / surgery

72 Pancreatic Neoplasms / diagnostic imaging

73 Ampulla of Vater

74 Jaundice, Obstructive / surgery

75 Common Bile Duct Neoplasms / surgery

$\begin{array}{lll}164 & 0.282 & 47.2002 \\ 164 & 0.282 & 47.4823 \\ 163 & 0.2803 & 47.7626 \\ 162 & 0.2786 & 48.0412 \\ 158 & 0.2717 & 48.3129 \\ 157 & 0.27 & 48.5829 \\ 151 & 0.2597 & 49.1057 \\ 150 & 0.258 & 49.3637 \\ 146 & 0.2511 & 49.6148 \\ 144 & 0.2476 & 49.8624 \\ 143 & 0.2459 & 50.1083 \\ 132 & 0.227 & 50.5692 \\ 131 & 0.2253 & 50.7945 \\ 130 & 0.2236 & 51.0181 \\ 128 & 0.2201 & 51.2382 \\ 127 & 0.2184 & 51.4566 \\ 127 & 0.2184 & 51.675 \\ 125 & 0.215 & 51.89 \\ 125 & 0.215 & 52.105 \\ 122 & 0.2098 & 52.3148 \\ 121 & 0.2081 & 52.5229 \\ 119 & 0.2047 & 52.7275 \\ 117 & 0.2012 & 52.9287 \\ 116 & 0.1995 & 53.1282 \\ 115 & 0.1978 & 53.326 \\ 114 & 0.1961 & 53.522 \\ 114 & 0.1961 & 53.7181 \\ 113 & 0.1943 & 53.9124 \\ 113 & 0.1943 & 54.1068 \\ 113 & 0.1943 & 54.3011 \\ 112 & 0.1926 & 54.4937 \\ 112 & 0.1926 & 54.6863 \\ 112 & 0.1926 & 54.8789 \\ 110 & 0.1892 & 55.0681 \\ 110 & 0.1892 & 55.2573 \\ 110 & 0.1892 & 55.4464 \\ 109 & 0.1875 & 55.6339 \\ 109 & 0.1875 & 55.8214 \\ 108 & 0.1857 & 56.0071 \\ 107 & 0.184 & 56.1911 \\ & & \\ 112 & & \end{array}$


76 Adenocarcinoma / surgery

77 Pancreatitis / diagnosis

78 Constriction, Pathologic

79 Diagnosis, Differential

80 Postoperative Complications / epidemiology

81 Constriction, Pathologic / surgery

82 Cholestasis, Extrahepatic / therapy

83 Pancreatitis, Chronic / complications
106

101

101

97

95

94

92

92
0.1823

0.1737

0.1737

0.1668

0.1634

0.1617

0.1582

0.1582
56.3734

56.5471

56.7208

56.8876

57.051

57.2126

57.3708

57.5291

$3 \quad{ }^{a}$ MeSH: Medical Subject Headings

$4 \quad$ b Proportion of the frequency among 19282 times' appearance. 


\section{Table 4 (on next page)}

The centrality and density of the 8 clusters about the application of stents in pancreatic diseases. 
1 Table 4 . The centrality and density of the 8 clusters

\begin{tabular}{lllll}
\hline & $\begin{array}{l}\text { Intra-class link } \\
\text { cluster }\end{array}$ & centrality-X & $\begin{array}{l}\text { Intra-class } \\
\text { link averages }\end{array}$ & density-Y \\
\hline 0 & 8.446666667 & -4.62712 & 33.16071429 & -22.7996 \\
1 & 15.29292929 & 2.219142 & 75.47272727 & 19.51241 \\
2 & 9.875586854 & -3.1982 & 31.62878788 & -24.3315 \\
3 & 24.98033126 & 11.90654 & 98.67032967 & 42.71001 \\
4 & 12.63963964 & -0.43415 & 68.26388889 & 12.30357 \\
5 & 13.39589041 & 0.322103 & 55.3 & -0.66032 \\
6 & 8.673972603 & -4.39982 & 27.58888889 & -28.3714 \\
7 & 11.28528529 & -1.7885 & 57.59722222 & 1.636902 \\
total & 13.07378775 & & 55.96031989 & \\
\hline
\end{tabular}

2 


\section{Table 5 (on next page)}

The cluster analysis of 8 clusters the application of stents in pancreatic diseases. 
1 Table 5. The cluster analysis of 8 clusters

\begin{tabular}{lll}
\hline Cluster & Number of MeSH terms ${ }^{\mathrm{a}}$ & Cluster analysis \\
\hline 0 & $23,34,56,58,69,72,79,82$ & Stents placement in pancreatic neoplasms \\
1 & $5,9,10,19,21,24,27,36,39,40,41$ & $\begin{array}{l}\text { The complications of stents placement in bile duct neoplasms and } \\
\text { pancreatic neoplasms }\end{array}$ \\
2 & $8,35,45,49,50,52,54,71,73,74,75,76$ & $\begin{array}{l}\text { postoperative complications after stent placement such as } \\
\text { pancreaticoduodenectomy }\end{array}$ \\
3 & $1,2,3,6,11,15,17,18,46,47,51,60,67,80$ & $\begin{array}{l}\text { Stents for the prevention of pancreatic fistula following } \\
\text { pancreaticoduodenectomy }\end{array}$ \\
4 & $12,13,14,22,28,37,48,61,65$ & $\begin{array}{l}\text { Prophylactic pancreatic duct stent can reduce the incidence of } \\
\text { post-ERCP pancreatitis (PEP) }\end{array}$ \\
5 & $4,25,29,31,32,33,38,42,57,77$ & The diagnosis, surgery and therapy of pancreatitis \\
6 & $16,43,55,59,62,64,68,78,81,83$ & Pancreatic ducts changes in patients with chronic pancreatitis \\
7 & $7,21,26,30,44,53,63,66,70$ & Stent placement in endoscopic pancreatic pseudocyst drainage \\
\hline
\end{tabular}

